\title{
RESIDUAL DOSES IN RECENT ALLUVIAL SEDIMENTS FROM THE ARDENNE (S BELGIUM)
}

\author{
DIMITRI VANDENBERGHE ${ }^{1, a}$, CILIA DERESE ${ }^{1}$ and GEOFFREY HOUBRECHTS ${ }^{2, b}$ \\ ${ }^{1}$ Laboratory of Mineralogy and Petrology (Luminescence Research Group), Geological Institute, Ghent University, \\ Krijgslaan 281 (S8), B-9000 Gent, Belgium \\ ${ }^{2}$ Unité de Géographie physique et Quaternaire - Hydrographie et géomorphologie fluviatile, Institut de Géographie, \\ B-4000 Liège, Belgium
}

\begin{abstract}
We report on our first investigations into the potential of optical dating for determining the rate of river flood sedimentation in the Ardenne region (S Belgium). Two samples collected from a recent alluvial deposit were used to investigate the extent of resetting in different particle size fractions of quartz (4-11 $\mu \mathrm{m}, 63-90 \mu \mathrm{m}, 90-125 \mu \mathrm{m}, 125-180 \mu \mathrm{m}, 180-212 \mu \mathrm{m}$ and 212-250 $\mu \mathrm{m})$ as well as in polymineral fine $(4-11 \mu \mathrm{m})$ grains. Both samples show satisfactory OSL and IRSL characteristics. The IRSL signals from the polymineral fine grains yield an equivalent dose $\left(D_{e}\right)$ of 3-4 Gy, while a $\mathrm{D}_{\mathrm{e}}$ of 0.3-0.6 Gy was measured using large aliquots of quartz. Small aliquot analyses of $63-90 \mu \mathrm{m}$ and $212-250 \mu \mathrm{m}$ quartz grains confirm that the coarser fraction contains more grains with lower $\mathrm{D}_{\mathrm{e}}$ 's. Furthermore, for a modern sample $\left(<3\right.$ years old), $\sim 60 \%$ of the aliquots yields a $\mathrm{D}_{\mathrm{e}}$ consistent with zero, indicating that these contain only well-bleached grains. These findings suggest that it might be possible to extract the true burial dose from dose distributions measured using small aliquots of coarse-grained (e.g. 212-250 $\mu \mathrm{m}$ ) quartz.
\end{abstract}

Keywords: optical dating, resetting, alluvial deposits, Ardenne

\section{INTRODUCTION}

Knowledge on the rate by which sediment is stored in floodplains is essential for understanding the impact of environmental and climatic forcing on the hydrosedimentary dynamics of rivers. In the Ardenne region (S Belgium; Fig. 1), several tracers have been used to estimate the age of the deposits in the alluvial plains, such as reworked tephra and metallurgical slag. By means of iron slag, for instance, it has been shown that sedimentation in the floodplains has been particularly important from the Middle Ages onwards (Houbrechts, 2005; Houbrechts and Petit, 2006). The sedimentation rates vary between 10 to $20 \mathrm{~cm} /$ century (depending on rivers and study sites), values which can be explained by important soil erosion related to the production of charcoal for the iron metallurgy between the $15^{\text {th }}$ and the $19^{\text {th }}$ century. Through the use of these tracers, however, only relative ages for sediment deposition are obtained; precise sedi-

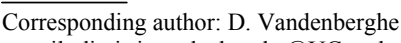
e-mail: dimitri.vandenberghe@UGent.be

ISSN 1897-1695 (online), 1733-8387 (print) (C) 2007 GADAM Centre, Institute of Physics, Silesian University of Technology.

All rights reserved. mentation rates cannot be determined, nor can fluctuations in sedimentation be recognised. Radiocarbon dating is often not applicable, either owing to the lack of suitable organic material or because the age range of interest is not covered by the technique. In any case, radiocarbon dating determines the time of sediment deposition indirectly as it uses associated material and/or intercalated horizons. The general absence of precise age information strongly hampers the interpretation of the deposits, as it prevents comparison of sedimentation rates between different historical periods, and hence evaluating the rivers' response to variations in climate and land-use.

Optical dating uses the constituent mineral grains of the sediment itself, and it allows determining the time of sediment deposition and accumulation directly. The technique rests on the assumption that the luminescence clock in the minerals is completely reset (or zeroed) during their exposure to sunlight prior to deposition. In fluvial environments, however, the sediment grains may have received only a limited exposure to daylight. A situation of incomplete resetting may lead to age overestimation,

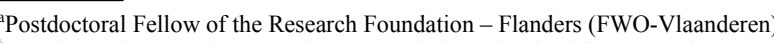
${ }^{b}$ Postdoctoral Researcher - National Foundation of Scientific Research (NFSR) Belgium 


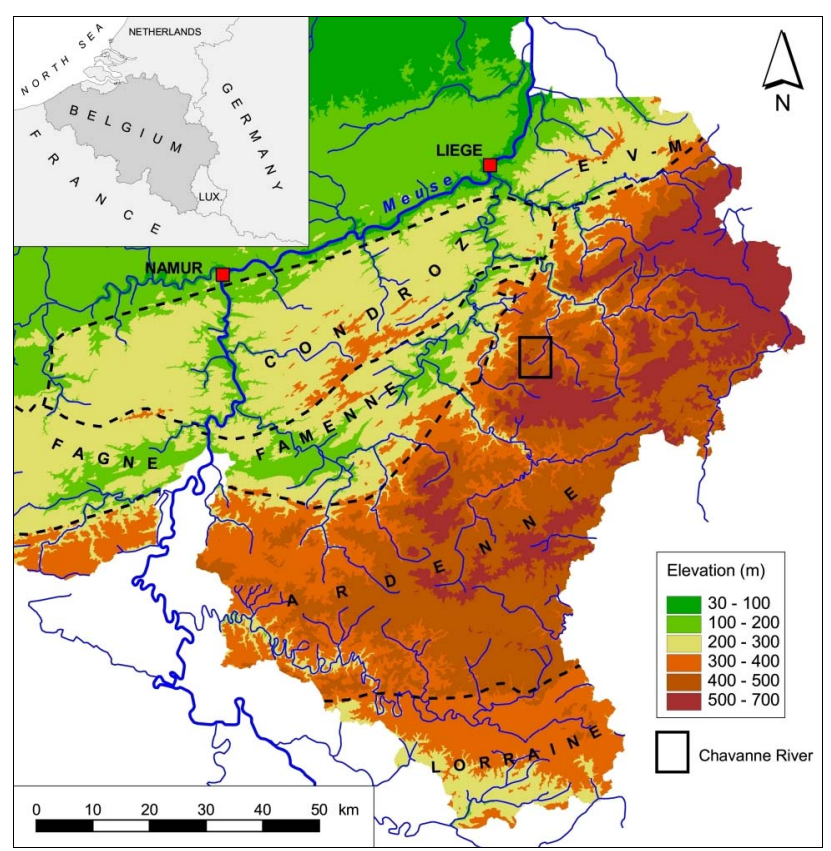

Fig. 1. Map showing the location of the Chavanne River in the Ardenne, S Belgium.

especially in the case of relatively young sediments for which any remnant signal might be a significant proportion of the signal acquired during burial. Significant improvements in both instrumentation and measurement technology have been made over the last few years, allowing the problem of incomplete resetting to be examined in great detail. This, in turn, has resulted in an increased number of studies in which optical dating could be successfully applied to fluvial deposits. Comprehensive reviews on the application of optical dating to fluvial deposits, and its intricacies, have been presented by Wallinga (2002), Murray and Olley (2002) and Jain et al. (2004).

Encouraged by the recent developments in optical dating technology, we initiated an explorative study, which aims at establishing whether or not the technique has potential for determining the rate of river flood sedimentation in the Ardenne region. In this paper, the first results of this pilot study are presented; more specifically, we
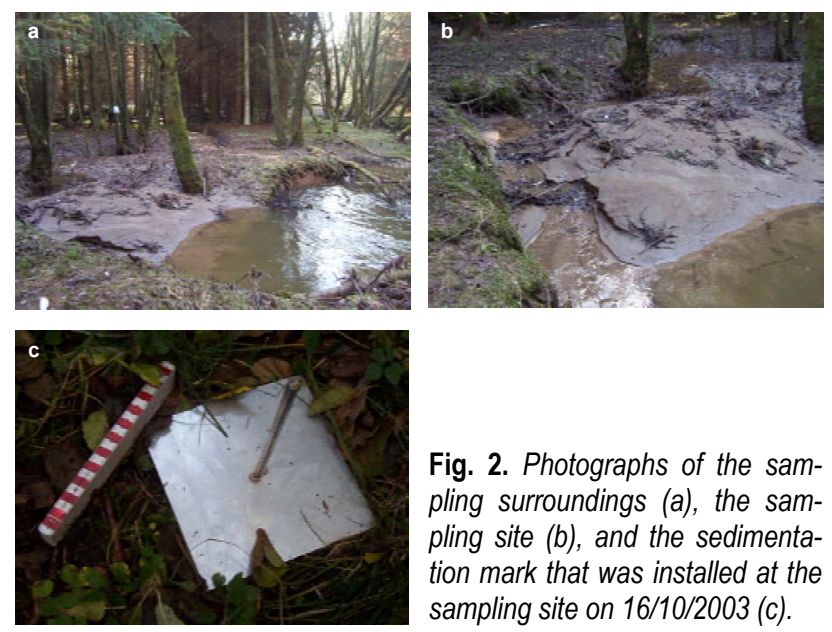

Fig. 2. Photographs of the sampling surroundings (a), the sampling site (b), and the sedimentation mark that was installed at the sampling site on 16/10/2003 (c). examine the extent of resetting in two recent alluvial samples from this specific deposition environment.

\section{GEOLOGICAL CONTEXT AND SAMPLING}

Rivers from the Ardenne (S Belgium; Fig. 1) are single channel rivers. They have quite a marked slope (varying from $0.001 \mathrm{~m} / \mathrm{m}$ for larger rivers to $0.02 \mathrm{~m} / \mathrm{m}$ for headwater streams), and generally develop meanders in narrow floodplains. The specific stream power of these rivers, for the bankfull discharge, is comprised between 25 and $150 \mathrm{~W} / \mathrm{m}^{2}$ (Petit et al., 2005). Their bedload consists mainly of phyllites, quartzites, schists and sandstones from the Cambrian and Eodevonian periods. According to rivers, the $\mathrm{D}_{50}$ varies from $1.5 \mathrm{~cm}$ to $15 \mathrm{~cm}$. The rivers are slowly moving laterally and are reworking the gravel layer inherited from the last cold periods (Juvigné, 1979). This layer is overlying the bedrock and is covered by sandy-silt deposits of one to two meters thick.

The samples used in this study were collected from a recent sandy alluvium deposited at the exit of a cut-off meander of the Chavanne River. The Chavanne is a small Ardenne river (catchment area $21 \mathrm{~km}^{2}$ ) belonging to the Meuse catchment (Fig. 1). In the upstream part, the Chavanne River is a gravel bed river $\left(\mathrm{D}_{50}=4.0 \mathrm{~cm}\right)$ confined to a single channel. The bedload consists mainly of phyllites, quartzites and arkoses from Ordovician and Eodevonian periods. The sampling site is situated $5 \mathrm{~km}$ from the spring. In this sector, the Chavanne River develops meanders in a narrow floodplain ( $\sim 50 \mathrm{~m}$ wide). The width of the river is about $4 \mathrm{~m}$ and the specific stream power is of the order of $40 \mathrm{~W} / \mathrm{m}^{2}$ for the bankfull discharge. The floodplain deposits consist mainly of sand and silt. According to the sedimentation study by Houbrechts and Petit (2006), $\sim 80 \mathrm{~cm}$ of sediment has been deposited on the floodplain since the $16^{\text {th }}$ century. Approximately $2 \mathrm{~km}$ downstream of the study site, the characteristics of the river suddenly change. The slope, which was comprised between 0.5 and $1 \%$ in the upper part, increases up to $2 \%$. The channel layout becomes subrectilinear and a step-pool system starts to appear. The $\mathrm{D}_{50}$ of the bed material increases to $10.0 \mathrm{~cm}$ and some boulders of arkose are disseminated in the bed.

The sampling surroundings and the sampling site are

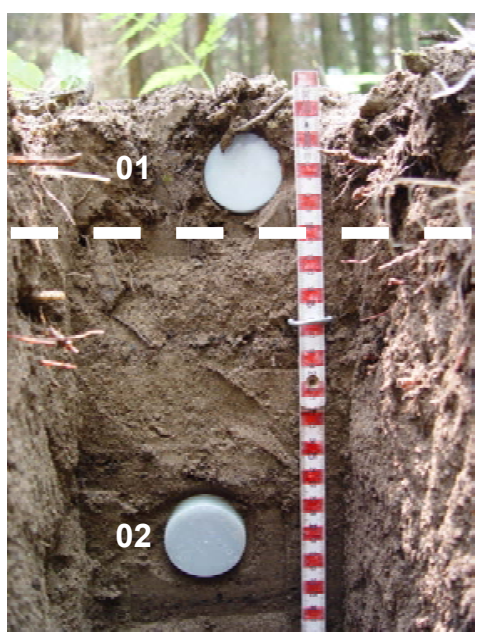

Fig. 3. Detail of the sampling. The dashed white line shows the level of the sedimentation mark on 05/07/2006. 
shown in Figs $\mathbf{2 a}$ and $\mathbf{2 b}$, respectively. A sedimentation mark was installed at the sampling site on $16^{\text {th }}$ October 2003 (Fig. 2c). On the $5^{\text {th }}$ of July 2006, a small profile pit was dug and two samples were collected by hammering stainless steel cylinders in the sediment. The first sample (GLL-061301) was collected immediately above the level of the sedimentation mark; the second sample (GLL061302) was collected some $20 \mathrm{~cm}$ below it (Fig. 3). While the first sample is known to be less than three years old, the latter is of unknown age. However, based on the high sedimentation rate as observed since the placement of the sedimentation mark (about $8 \mathrm{~cm}$ in less than three years), it is believed to be less than a few decades old.

\section{SAMPLE PREPARATION AND ANALYTICAL FACILITIES}

In the laboratory, different particle size fractions of quartz (4-11 $\mu \mathrm{m}, 63-90 \mu \mathrm{m}, 90-125 \mu \mathrm{m}, 125-180 \mu \mathrm{m}$, $180-212 \mu \mathrm{m}, 212-250 \mu \mathrm{m})$ as well as polymineral fine $(4-11 \mu \mathrm{m})$ grains were extracted from the inner material of the sampling tubes using conventional sample preparation techniques (Frechen et al., 1996; Lang et al., 1996; Mauz et al., 2002). The purity of the quartz extracts was confirmed by the absence of a significant infrared stimulated luminescence (IRSL) response to a large regenerative beta dose. For measurement, coarse $(>63 \mu \mathrm{m})$ quartz grains were mounted on stainless steel discs; the fine (4-11 $\mu \mathrm{m})$ grains were deposited on aluminium discs through settling from a suspension in acetone.

Luminescence measurements were performed in automated Risø readers. Quartz was stimulated with blue $(470 \pm 30 \mathrm{~nm})$ light and the luminescence emissions were detected through a $7.5 \mathrm{~mm}$ thick Hoya U-340 filter. Polymineral fine grains were stimulated using IR-diodes $(875 \mathrm{~nm})$ and the IRSL-emission was detected through a BG39/CN7-59/GG-400 filter set. Details on the measurement apparatus can be found in Bøtter-Jensen et al. (2003).

\section{LUMINESCENCE CHARACTERISTICS}

The luminescence characteristics of all grain and mineral fractions were investigated using large $(8-10 \mathrm{~mm}$ diameter) aliquots and using the single-aliquot regenerative-dose (SAR) procedure (Murray and Wintle, 2000).

The quartz measurements were carried out using a preheat of $10 \mathrm{~s}$ at $180^{\circ} \mathrm{C}$ and a cutheat to $160^{\circ} \mathrm{C}$. The SAR procedure involved four regenerative doses $(0.5$, $0.9,1.4$, and $1.9 \mathrm{~Gy}$ ) and a zero dose, a repeated first regenerative dose $(0.5 \mathrm{~Gy})$ and a fifth regenerative dose (2.3 Gy). Additionally, a second measurement of the response to the highest regenerative dose was made; this time the sensitivity to stimulation with infrared light was checked before stimulation with the blue diodes. The purpose of this treatment was to allow identification of aliquots with a significant feldspar contamination. The size of the test dose was equal to the highest regenerative dose $(2.3 \mathrm{~Gy})$. Optical stimulation was for $40 \mathrm{~s}$ at $125^{\circ} \mathrm{C}$ and the initial $0.3 \mathrm{~s}$ of the OSL decay curves was used in further calculations, minus a background derived from the last $4 \mathrm{~s}$ of stimulation. The same background as calculated for the natural and regenerated signals was used for the corresponding test dose signals. To minimize possible effects of recuperation, a high temperature stimulation (for $40 \mathrm{~s}$ at $280^{\circ} \mathrm{C}$ ) was added after each measurement of the test dose response (Murray and Wintle, 2003).

For the polymineral fine grains, a preheat treatment of $1 \mathrm{~min}$ at $250^{\circ} \mathrm{C}$ was applied after both regenerative and test doses (Auclair et al., 2003). The SAR procedure involved measuring the response to four regenerative doses (3, 6, 9 and 12 Gy), a zero dose, a repeated first regenerative dose $(3 \mathrm{~Gy})$ and a fifth regenerative dose (15 Gy). The size of the test dose was 6 Gy. Stimulation of the polymineral fine grains was for $100 \mathrm{~s}$ at $40^{\circ} \mathrm{C}$ using the IR-diodes. Calculations used the initial $0.8 \mathrm{~s}$ of the IRSL-decay curve minus a background derived from the last $10 \mathrm{~s}$ of stimulation; the same background as calculated for the natural and regenerated signals was used for the corresponding test dose signals. An elevated temperature infrared bleach $\left(40 \mathrm{~s}\right.$ at $\left.290^{\circ} \mathrm{C}\right)$ was inserted after each measurement of the test dose response.

Representative luminescence decay and growth curves are shown in Fig. 4 for an aliquot of 212-250 $\mu \mathrm{m}$ quartz (a), 4-11 $\mu \mathrm{m}$ quartz (b), and polymineral fine $(4-11 \mu \mathrm{m})$ grains (c) extracted from sample GLL-061301. All grain and mineral fractions emitted clearly detectable natural luminescence signals. The growth of the signals with dose could be well approximated by linear or single saturating exponential functions. In general, both samples behaved well in the SAR-OSL and SAR-IRSL protocols, with recycling ratios close to unity and recuperation less than a few $\%$ of the corrected natural signal. In all experiments reported in the following, a measured dose value was accepted if the recycling ratio, the recuperation and the IRSL/BLSL ratio (in the case of quartz) did not exceed a threshold set at $10 \%$.

One of the main problems specific to the dating of young material is thermal transfer, which is the transfer of charge by heating from light-insensitive (or less lightsensitive) but thermally stable traps, into light-sensitive traps. If significant, it leads to an overestimation of the equivalent dose $\left(D_{e}\right)$ and hence the age. From the description of the phenomenon, it can be expected to be more of a concern for younger samples, and even more so for those deposited in environments where exposure to sunlight is limited. Thermal transfer has long been considered a limitation to the dating of young samples. In their review of twenty-one studies dealing with the application of optical dating to young $(<1000$ years $)$ sediments, however, Madsen and Murray (personal communication) showed that thermal transfer is usually negligible provided that the preheat is low $\left(<200^{\circ} \mathrm{C}\right)$. The presence and significance of thermal transfer in our quartz samples was tested using the 212-250 $\mu \mathrm{m}$ quartz fractions of samples GLL-061301 and -02. Aliquots were first bleached twice for $100 \mathrm{~s}$ using the blue diodes at room temperature; the two bleaching steps were separated by a $10 \mathrm{ks}$ pause. The aliquots were then measured using the SAR protocol as outlined in the above, employing a range of different preheat temperatures. The results are shown in Fig. 5. It can be seen that thermal transfer sets in at preheat temperatures of as low as $200^{\circ} \mathrm{C}$, and becomes 

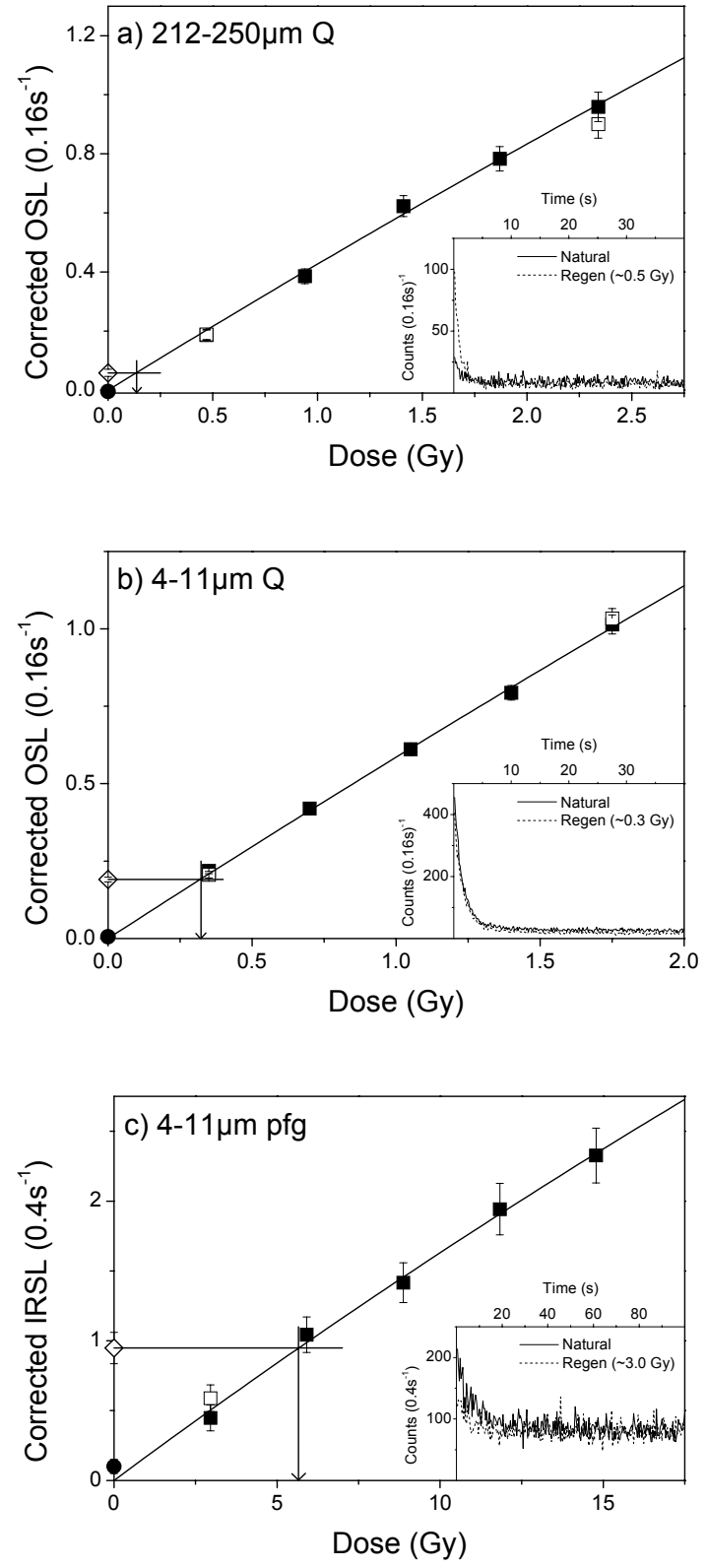

Fig. 4. SAR growth curves and illustrative luminescence decay curves (inset) for an aliquot of a) 212-250 $\mu \mathrm{m}$ quartz, b) 4-11 $\mu \mathrm{m}$ quartz and c) polymineral fine $(4-11 \mu \mathrm{m})$ grains extracted from sample GLL061301. The solid and open squares represent regenerative dose and recycling points, respectively; the open diamond is the natural signal and the solid circle the response to a zero dose.

increasingly important at higher preheat temperatures. Based on these findings, a preheat regime of $10 \mathrm{~s}$ at $180^{\circ} \mathrm{C}$ was adopted in all further experiments. The thermally transferred dose from this preheat treatment was found to be $0.008 \pm 0.008 \mathrm{~Gy}$ and $0.024 \pm 0.008 \mathrm{~Gy}$ for samples GLL-061301 and -02, respectively. It can be added that the amount of charge transferred by the $180^{\circ} \mathrm{C}$ preheat was also quantified for the $63-90 \mu \mathrm{m}$ quartz extracts; samples GLL-061301 and -02 yielded values of $0.006 \pm 0.003$ Gy and $0.002 \pm 0.003$ Gy, respectively. The difference in results obtained for sample GLL-061302 (about an order of magnitude) is not understood at present.

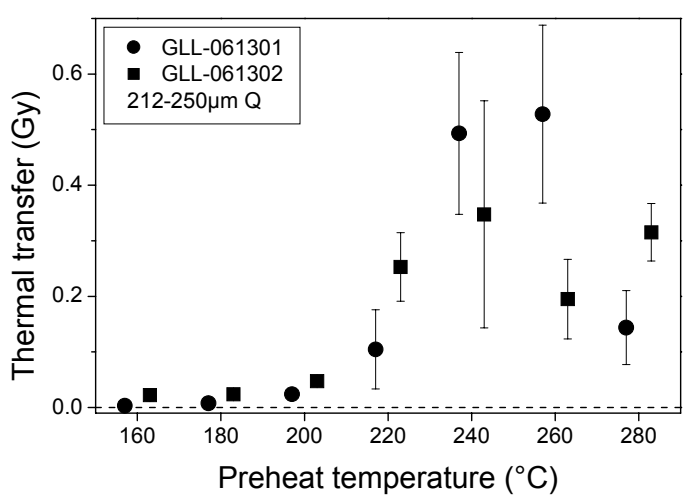

Fig. 5. Dependence of thermally transferred dose on preheat temperature for 212-250 $\mu \mathrm{m}$ quartz grains extracted from samples GLL061301 (solid circles) and -02 (solid squares). Shown are the averages \pm 1 standard error. The dashed line (eye guide) represents a thermally transferred dose equal to $0 \mathrm{~Gy}$.

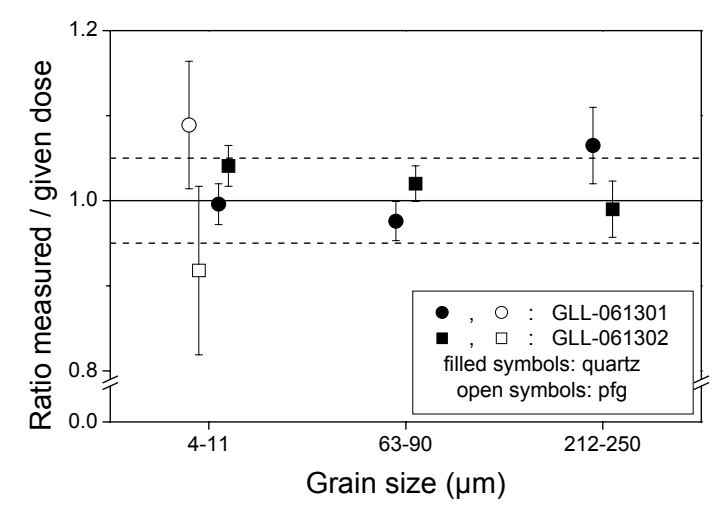

Fig. 6. Data from the dose recovery experiments for samples GLL061301 (circles) and -02 (squares). The open symbols refer to the results obtained on the polymineral fine $(4-11 \mu \mathrm{m})$ grains. Shown are the averages \pm 1 standard error. The solid and dashed lines are meant as eye guides and represent a measured/given dose ratio equal to unity and a $5 \%$ deviation of this ratio from unity, respectively.

For the polymineral fine grains, a similar experiment was carried out in which aliquots were first bleached for 1 hour in a Hönle SOL 2 solar simulator, and were subsequently measured using SAR as outlined in the above. These experiments, however, were carried out for a preheat of $1 \mathrm{~min}$ at $250^{\circ} \mathrm{C}$ only. A residual SAR-IRSL dose of 2.1 \pm 0.2 Gy was measured for sample GLL-061301; sample -02 yielded a dose of $2.7 \pm 0.3 \mathrm{~Gy}$.

The overall performance of the SAR protocol was evaluated through dose recovery tests (Murray and Wintle, 2003). The experiments were carried out for both samples, and for quartz grains from the 4-11, 63-90 and $212-250 \mu \mathrm{m}$ fraction, as well as for the polymineral 4-11 $\mu \mathrm{m}$ grains. Aliquots of quartz were bleached twice using the blue diodes for $100 \mathrm{~s}$ at room temperature, separated by a $10 \mathrm{ks}$ pause; polymineral fine grains were bleached for 1 hour in a Hönle SOL 2 solar simulator. After bleaching, the aliquots were given a dose equal to the expected natural dose, and were measured using SAR. The results are summarised in Fig. 6. For both samples and all fractions, the given doses can be recovered to within $5 \%$. The overall $(n=2)$ average measured to given 
dose ratio obtained with the SAR-OSL protocol is $1.01 \pm 0.02$. The SAR-IRSL protocol yields an overall dose recovery of $1.00 \pm 0.09$, but it should be noted that the 2-3 Gy residual dose (see above) was subtracted from the measured dose values. The results from the dose recovery tests indicate that the SAR-OSL and SAR-IRSL protocols are suitable for determining the $\mathrm{D}_{\mathrm{e}}$ in the samples.

\section{EQUIVALENT DOSE DETERMINATION}

\section{Large aliquots}

In a following series of experiments, the SAR protocol was used to determine the $\mathrm{D}_{\mathrm{e}}$ in large aliquots of polymineral fine grains (10 mm diameter aliquots) and of quartz of different grain sizes ( $8 \mathrm{~mm}$ diameter aliquots). These experiments aimed at establishing whether or not grains of different size and mineralogy are bleached to a different degree. At least 16 aliquots were measured for each grain size fraction, with the exception of the 4-11 $\mu \mathrm{m}$ quartz fraction, for which 11 aliquots were measured. Equivalent dose determination used the SAR protocol as outlined in Chapter 4.

In Fig. 7a the average $D_{\mathrm{e}}$ 's ( \pm 1 standard error) are plotted versus grain size. For both samples, the polymineral fine grains clearly yield significantly higher equivalent doses (the residual dose of 2-3 Gy has been subtracted from all SAR-IRSL $D_{\mathrm{e}}$ 's plotted in Fig. 7). Quartz yields much lower $D_{e}$ values, and no systematic variation of average dose with grain size is apparent. The individual $D_{e}$ values for all grain and mineral fractions are shown in Fig. 7b. It can be seen that all aliquots yield measurable doses. The results for the $4-11 \mu \mathrm{m}$ fraction are very reproducible, although the poor luminescence sensitivity of the polymineral fine grains limited the measurement precision (see inset of Fig. 4c). Each of the coarser $(>63 \mu \mathrm{m})$ fractions exhibits some spread in the measured doses. It indicates that all aliquots consist of a mixture of grains which have been reset to various degrees. Obviously, the average number of grains on each aliquot depends on the size of the grains. Whereas there may be tens of thousands of 4-11 $\mu \mathrm{m}$ grains on a large aliquot, the number of $212-250 \mu \mathrm{m}$ grains is probably only of the order of a few hundred. As the scale of analysis increases, one may expect that the effects of incomplete resetting are progressively averaged out within each disc, resulting in more reproducible results which systematically overestimate the true burial dose. This is nicely illustrated by comparing the data obtained for the 4-11 $\mu \mathrm{m}$ quartz with those for the coarser quartz fractions. It is interesting to note, however, that the effect of dose heterogeneity being averaged out is not reflected within the 63 to $250 \mu \mathrm{m}$ range. Apart from some obvious outliers, the results for the coarser grains generally appear at least as reproducible as for the finest sand-sized quartz, and they verge towards lower $\mathrm{D}_{\mathrm{e}}$ values.

The most recent sample (GLL-061301) provides most information on the degree of resetting. An average SARIRSL $D_{e}$ value $( \pm 1$ standard error) of $3.3 \pm 0.2$ Gy was obtained for the polymineral fine grains, while the average OSL- $\mathrm{D}_{\mathrm{e}}$ for the fine-grained quartz is $0.33 \pm 0.01 \mathrm{~Gy}$. Rejecting the four obvious outliers ( $>1 \mathrm{~Gy}$ ) for the
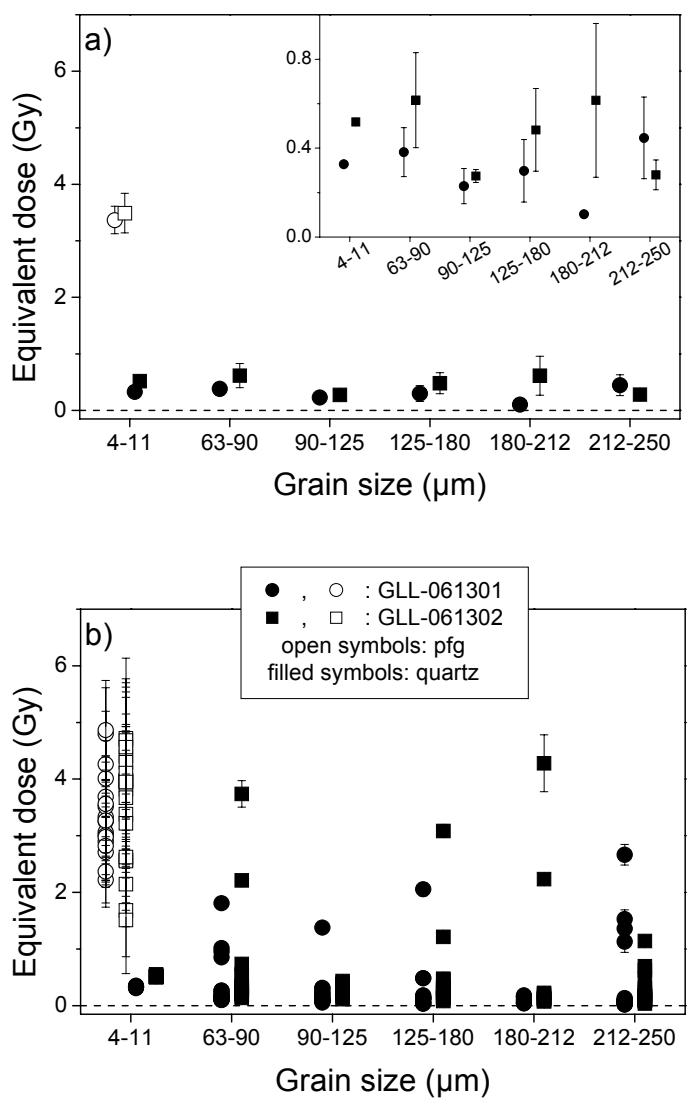

Fig. 7. a) Average $D_{e}$ values ( \pm 1 standard error) in large aliquots of polymineral fine grains (open symbols), and quartz of different particle sizes (filled symbols). The circles refer to the data for sample GLL061301, the squares to those for sample GLL-061302. The dashed line at an equivalent dose equal to zero is meant as an eye guide. The inset shows the same data for different grain sizes of quartz only. b) Individual $D_{e}$ 's of the data shown in a); error bars represent 1 sigma and arise from counting statistics and the fitting procedure (for details see Vandenberghe, 2004).

212-250 $\mu \mathrm{m}$ fraction results in an average $\mathrm{D}_{\mathrm{e}}$ of $0.07 \pm 0.01 \mathrm{~Gy}$; including them gives an average dose of $0.4 \pm 0.2 \mathrm{~Gy}$.

\section{Small aliquots}

To examine the issue of incomplete resetting to greater detail, the distribution of $\mathrm{D}_{\mathrm{e}}$ in quartz from two particle size fractions (63-90 and 212-250 $\mu \mathrm{m}$ ) was investigated using small ( $2 \mathrm{~mm}$ diameter) aliquots. These investigations were carried out on the modern sample GLL061301 ( $<3$ years old). On average (estimated by counting the number of grains on 10 discs), the $63-90 \mu \mathrm{m}$ aliquots contained $\sim 500$ grains; the $212-250 \mu \mathrm{m}$ aliquots contained $\sim 30$ grains. The $\mathrm{D}_{\mathrm{e}}$ distributions were measured using the SAR protocol as outlined in the above. For each grain size fraction, 120 small aliquots were analysed. In addition to the aforementioned criteria, $D_{e}$ values were included in the distributions if the relative error on the test dose signal did not exceed $30 \%$. The results are represented as histograms in Fig. 8.

The results obtained on the 63-90 $\mu \mathrm{m}$ fraction are clearly more scattered and spread out over a larger dose range, leading to an asymmetric distribution (Fig. 8a). 


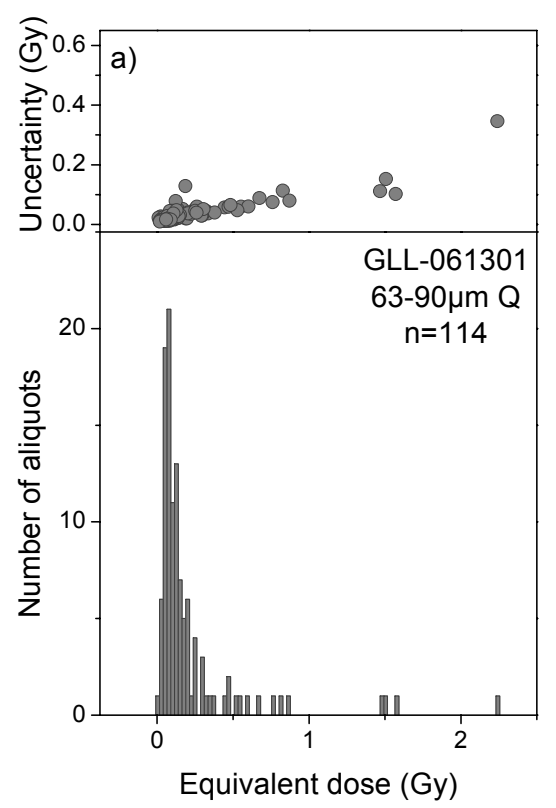

Fig. 8. $D_{e}$ results obtained using small aliquots of 63-90 $\mu \mathrm{m}$ and 212-250 $\mu \mathrm{m}$ quartz grains extracted from sample GLL061301. For each grain size, 120 aliquots were measured; $n$ is the number that could be accepted. A plot of uncertainty versus $D_{e}$ is shown above each histogram; the median from this uncertainty distribution was used for binning the data (Lepper et al., 2000).
The unweighted average $D_{e}( \pm 1$ standard error $)$ is $0.22 \pm 0.03 \mathrm{~Gy}$; the median value is $0.11 \mathrm{~Gy}$. The $\mathrm{D}_{\mathrm{e}}$ 's obtained for the coarser 212-250 $\mu \mathrm{m}$ fraction, on the other hand, appear symmetrically distributed around a central value close to zero (Fig. 8b). The unweighted average $D_{e}$ is $0.06 \pm 0.02 \mathrm{~Gy}$, with a median of $0.04 \mathrm{~Gy}$. Within 1 sigma uncertainty (which includes counting statistics and the uncertainty in the growth curve that has been fitted), $\sim 60 \%$ of the $212-250 \mu \mathrm{m}$ aliquots yield a $D_{e}$ consistent with $0 \mathrm{~Gy}$; in the case of the 63-90 $\mu \mathrm{m}$ aliquots, this is only $2 \%$. The small aliquot results confirm that the coarser fraction contains more grains with lower $\mathrm{D}_{\mathrm{e}}$ 's, and that a relatively large percentage of these coarser grains was completely reset. The average dose ( \pm 1 standard error) and median value of the lowest $60 \%$ of the $212-250 \mu \mathrm{m}$ aliquots are $0.009 \pm 0.017 \mathrm{~Gy}$ and $0.005 \mathrm{~Gy}$, respectively.

To test the general performance of the measurement procedure for application to small aliquots, a dose recovery test was performed as well. This test was applied to 120 small aliquots of 212-250 $\mu \mathrm{m}$ quartz grains extracted from sample GLL-061301, and it was carried out exactly as outlined in Chapter 4. The results are shown in Fig. 9. The distribution of measured doses is symmetric, with an unweighted average ( \pm 1 standard error) of $0.45 \pm 0.02$ Gy and a median of $0.44 \mathrm{~Gy}$. The ratio of the unweighted average measured dose to the given dose is $0.97 \pm 0.03$. The dose recovery results demonstrate that the measurement procedure yields accurate $D_{e}$ values for small aliquots. Compared to the natural doses, the given doses were measured with a higher precision owing to the larger dose of 0.47 Gy that was administered in the laboratory. Therefore, the measured dose distribution is somewhat tighter. Apart from that, the shape of the dose distribution obtained on quartz grains which were completely zeroed in the laboratory is quite similar to that of the natural dataset (Fig. 8b).

In a final experiment, the $\mathrm{D}_{\mathrm{e}}$ distribution in sample GLL-061302 was also measured using 120 small aliquots of 212-250 $\mu \mathrm{m}$ quartz grains. The results are shown as a histogram in Fig. 10. The unweighted average ( \pm 1 standard error) of this distribution is $0.39 \pm 0.20$ Gy with a median of $0.06 \mathrm{~Gy}$. Rejecting the four obvious outliers $\left(D_{\mathrm{e}}>2 \mathrm{~Gy}\right)$ yields an unweighted average $( \pm 1$ standard error) of $0.11 \pm 0.02$ Gy and a median of 0.05 Gy. Apart from these outliers at higher doses, the shape of the $\mathrm{D}_{\mathrm{e}}$ distribution is very similar (if not identical) to that obtained for the $212-250 \mu \mathrm{m}$ aliquots of sample -01 (Fig. 8b). The lowest $60 \%$ of the aliquots give an unweighted average $D_{e}$ of $0.013 \pm 0.010$ Gy and a median value of $0.031 \mathrm{~Gy} ; 60 \%$ is the fraction of aliquots which, within 1 sigma, yielded a dose consistent with zero in sample GLL-061301.

\section{DISCUSSION AND CONCLUSIONS}

The luminescence characteristics of two recent alluvial samples from the Ardenne region (S Belgium) were investigated in terms of behaviour in the SAR protocol, dose response and dose recovery. It is concluded that the employed SAR-IRSL and SAR-OSL protocols are suitable for determining the $\mathrm{D}_{\mathrm{e}}$ in polymineral fine, and fine and coarse quartz grains, respectively. Sensitivity changes occurring throughout a SAR measurement sequence are accurately corrected for, and a known dose given prior to any heating can be accurately measured. A relatively low preheat of $10 \mathrm{~s}$ at $180^{\circ} \mathrm{C}$ does not appear to cause a significant transfer of charge in the quartz samples. In the case of the polymineral fine grains, however, residual doses of 2-3 Gy were obtained after preheating laboratory-zeroed samples for $1 \mathrm{~min}$ at $250^{\circ} \mathrm{C}$. Dose recovery results lend some validity to an empirical correction procedure in which this residual dose is simply subtracted from the measured dose.

The results from the large and small aliquot analyses (Figs 7 and 8) indicate that the coarsest quartz grains $(212-250 \mu \mathrm{m})$ yield the lowest $\mathrm{D}_{\mathrm{e}}$ values. This grain size dependency has been reported before (summarised by 


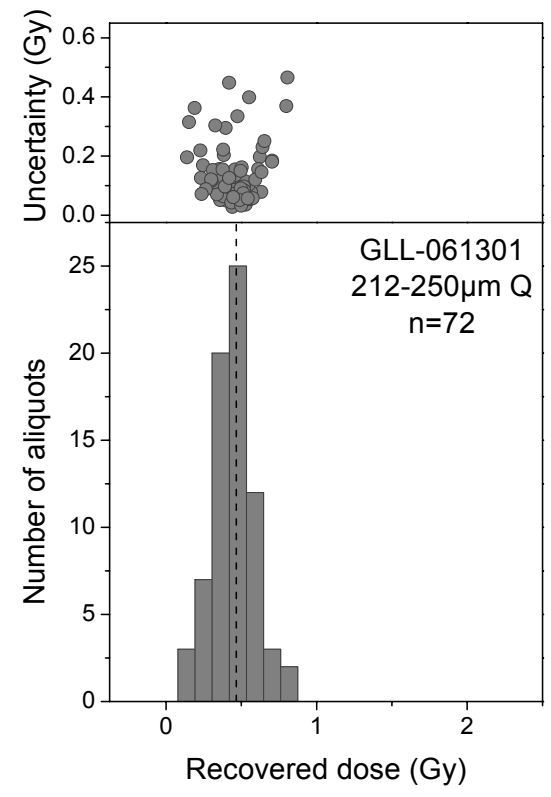

Fig. 9. Results from dose recovery experiments using small aliquots of 212-250 $\mu m$ quartz grains extracted from sample GLL061301. The given dose (0.47 Gy) is indicated in the histogram by the dashed line.
Wallinga, 2002; see also Truelsen and Wallinga, 2003 and Alexanderson, 2007). IRSL signals from polymineral fine grains yield equivalent doses which are at least one order of magnitude higher than those measured using quartz. The same observation has been reported by Fuchs et al. (2005) in their study of recent river flood sediments in Saxony (Germany).

In general, the small aliquot distributions measured using 212-250 $\mu \mathrm{m}$ quartz grains are wide but relatively symmetric (Figs 8b and 10). Outliers towards the high dose end of the distribution can be attributed to the presence of incompletely reset grains. Comparison of Figs $\mathbf{8 b}$ and 10 with previously published $\mathrm{D}_{\mathrm{e}}$ distributions for young fluvial material (e.g. Olley et al., 1997, their Fig. 2) suggests that the two samples investigated in this study are much better reset notwithstanding the much smaller scale of the fluvial system. For the modern alluvial sample $(<3$ years old, sample GLL-061301), about $60 \%$ (1 sigma) of the small aliquots yields a $\mathrm{D}_{\mathrm{e}}$ consistent with zero, and the distributions of both samples show similarity to those measured for aeolian sands (see e.g. Olley et al., 1997; Vandenberghe et al., 2003; accepted; Vandenberghe, 2004). It is not understood why the resetting process appears to have been more efficient than in larger drainage systems. One plausible explanation is that a large proportion of the sediment grains has been repeatedly reworked, hereby receiving a cumulative exposure to light which resulted in a complete resetting of the luminescence clock.

As the purpose of this study was to examine the extent of resetting rather than obtaining optical ages for the samples, no precise determination of the dose-rate was carried out. Nevertheless, it is interesting to have an estimate of the ages that corresponds to the observed doses. Assuming a dose rate of $2.84 \pm 0.05 \mathrm{mGy}$ year $^{-1}$ (based on Vandenberghe, unpublished gamma-ray spectrometry data), the overall large aliquot value of $0.4 \pm 0.2 \mathrm{~Gy}$ for the 212-250 $\mu \mathrm{m}$ grains of sample GLL-061301 (see Chapter 5, Large aliquots) corresponds to an optical age of

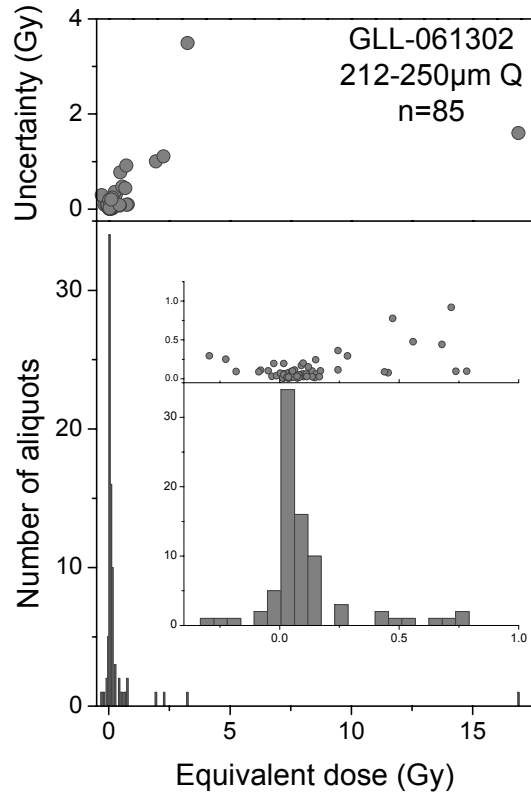

Fig. 10. $D_{e}$ results obtained using small aliquots of 212-250 $\quad \mu m$ quartz grains extracted from sample GLL061302. The inset shows an enlargement of the same data up to $1.0 \mathrm{~Gy}$.
$154 \pm 65$ years; rejecting the four aliquots with a $D_{e}>1$ Gy leads to an age of $24 \pm 4$ years. The age calculated from the lowest $60 \%$ of the small aliquot dose distribution gives an age of $3 \pm 6$ years for this sample. For sample GLL-061302, the overall unweighted average $D_{e}$ of the small $212-250 \mu \mathrm{m}$ aliquot distribution $(0.11 \pm 0.02 \mathrm{~Gy})$ leads to an age of $139 \pm 73$ years. Rejecting the four obvious outliers $\left(D_{e}>2\right.$ Gy) gives an age of $38 \pm 8$ years, and the unweighted average and median of the lowest $60 \%$ of the aliquots results in ages of $5 \pm 4$ years and $\sim 11$ years, respectively. Apart from the age of about 140 years, all small-aliquot age estimates for sample GLL-061302 fall well within the expectations (see Chapter 2). As the lowest $60 \%$ of small aliquots of the representative modern analogue yields a dose (and hence age) consistent with zero, it is likely that the same way of analysing the data gives the best estimates of burial dose and age for sample GLL-061302 as well. However, it remains to be established whether this procedure is generally applicable to alluvial sediments deposited in the Ardenne region.

It is concluded that optical dating of coarse quartz grains holds potential for establishing the chronology of alluvial deposits in the Belgian Ardenne. The findings for the two samples investigated in the present study indicate that conventional large aliquot SAR analyses would allow obtaining accurate chronologies from about 1000 years onwards. For younger samples, luminescence analysis using small aliquots is the best approach. It is acknowledged that further research is necessary both to improve our understanding of resetting of the luminescence clock in Ardennes' alluvial sediments and to improve the accuracy of dose distribution analysis. To this purpose, small-aliquot and single-grain investigations on known-age samples will be carried out in the near future.

\section{ACKNOWLEDGEMENTS}

Thanks are due to Gilles Velghe and Nicole Selen for their valuable technical assistance. We greatly appreci- 
ated Eric Hallot's assistance in the field. Grateful acknowledgement is made to the Fund for Scientific Research - Flanders (DV), the Special Fund of the Ghent University (CD) and the National Foundation of Scientific Research $(\mathrm{GH})$ for financial support. Anni Madsen and Andrew Murray are thanked for providing us with an unpublished manuscript of their review paper. We also thank Jan-Pieter Buylaert and Andrew Murray for stimulating discussions.

This paper is dedicated to Prof. Dr. Frans De Corte, as a souvenir to his retirement and in recognition of almost ten years of close, fruitful and amicable collaboration.

\section{REFERENCES}

Alexanderson H, 2007. Residual OSL signals from modern Greenlandic river sediments. Geochronometria 26: 1-9, DOI 10.2478/v10003007-0001-6.

Auclair M, Lamothe M and Huot S, 2003. Measurement of anomalous fading for feldspar IRSL using SAR. Radiation Measurements 37(4-5): 487-492, DOI 10.1016/S1350-4487(03)00018-0.

Bøtter Jensen L, Andersen CE, Duller GAT and Murray AS, 2003. Developments in radiation, stimulation and observation facilities in luminescence measurements. Radiation Measurements 37(4-5): 535-541, DOI 10.1016/S1350-4487(03)00020-9.

Frechen M, Schweitzer U and Zander A, 1996. Improvements in sample preparation for the fine grain technique. Ancient TL 14(2): 15-17.

Fuchs M, Straub J and Zöller L, 2005. Residual luminescence signals of recent river flood sediments: a comparison between quartz and feldspar of fine- and coarse-grain sediments. Ancient TL 23: 25-30

Houbrechts G, 2005. Utilisation des macroscories et des microscories en dynamique fluviale: application aux rivières du massif ardennais (Belgique) (Using macroscopic and microscopic slags in fluvial dynamics: application to Ardenne's rivers (Belgium)). PhD thesis, University of Liège: 328 pp (in French).

Houbrechts G and Petit F, 2006, Utilisation des microscories métallurgiques comme traceur de la sédimentation dans les plaines alluviales ardennaises (Use of metallurgic microscopic slags as tracer for sedimentation in the alluvial plains of the Ardenne). L'érosion entre société, climat et paléoenvironnement, Collection Nature et Société, Presses universitaires Blaise Pascal 3: 93-98 (in French).

Jain M, Murray AS and Bøtter-Jensen L, 2004. Optically stimulated luminescence dating: how significant is incomplete light exposure in fluvial environments? Quaternaire 15: 143-157.

Juvigné E, 1979. L'encaissement des rivières ardennaises depuis le début de la dernière glaciation (Downcutting of Ardenne's rivers since the beginning of the last glaciation). Zeitschrift für Geomorphologie 23: 291-300 (in French).

Lang A, Lindauer S, Kuhn R and Wagner GA, 1996. Procedures used for optically and infrared stimulated luminescence dating of sediments in Heidelberg. Ancient TL 14(3): 7-11.

Lepper K, Agersnap Larsen N, McKeever SWS, 2000. Equivalent dose distribution analysis of Holocene eolian and fluvial quartz sands from Central Oklahoma. Radiation Measurements 32(5-6): 603608, DOI 10.1016/S1350-4487(00)00093-7.

Mauz B, Bode T, Mainz E, Blanchard H, Hilger W, Dikau R and Zöller L, 2002. The luminescence dating laboratory at the University of Bonn: equipment and procedures. Ancient TL 20(2): 53-61.

Murray AS and Olley JM, 2002. Precision and accuracy in the optically stimulated luminescence dating of sedimentary quartz: a status review. Geochronometria 21: 1-16.

Murray AS and Wintle AG, 2000. Luminescence dating of quartz using an improved single-aliquot regenerative-dose protocol. Radiation Measurements 32(1): 57-73, DOI 10.1016/S1350-4487(99)00253$\mathrm{X}$.

Murray AS and Wintle AG, 2003. The single aliquot regenerative dose protocol: potential for improvements in reliability. Radiation Measurements 37(4-5): $\quad 377-381$, DOI $10.1016 / \mathrm{S} 1350$ 4487(03)00053-2.

Olley JM, Caitcheon G and Murray AS, 1998. The distribution of apparent dose as determined by optically stimulated luminescence signals in small aliquots of fluvial quartz: implications for dating young sediments. Quaternary Science Reviews 17(11): 1033-1040, DOI 10.1016/S0277-3791(97)00090-5.

Petit F, Gob F, Houbrechts G and Assani AA, 2005. Critical specific stream powers in gravel-bed rivers. Geomorphology 69(1-4): 92101, DOI 10.1016/j.geomorph.2004.12.004.

Truelsen JL and Wallinga J, 2003. Zeroing of the OSL signal as a function of grain size: investigating bleaching and thermal transfer for a young fluvial sample. Geochronometria 22: 1-8.

Vandenberghe D, 2004. Investigation of the optically stimulated luminescence dating method for application to young geological sediments. PhD thesis, Ghent University: 358pp.

Vandenberghe D, Hossain SM, De Corte F and Van den haute P, 2003. Investigations on the origin of the equivalent dose distribution in a Dutch coversand. Radiation Measurements 37(4-5): 433-439, DOI 10.1016/S1350-4487(03)00051-9.

Vandenberghe D, Vanneste K, Verbeeck K, Paulissen E, Buylaert JP, De Corte F. and Van den haute P, accepted. Late Weichselian and Holocene earthquake events along the Geleen fault in NE Belgium: OSL age constraints. Quaternary International.

Wallinga J, 2002. Optically stimulated luminescence dating of fluvial deposits: a review. Boreas 31(4): 303-322, DOI 10.1080/030094802320942536. 